\title{
Coordination of Advertising Free Riding in Hybrid Channel Supply Chain
}

\author{
Jin Sha, Aihu Wang, Ting Lv, and Wenling Wu \\ School of Business Administration, South China University of Technology, Guangzhou, Guangdong 510640, China \\ Correspondence should be addressed to Aihu Wang; bmawang@scut.edu.cn
}

Received 26 December 2015; Revised 1 May 2016; Accepted 15 May 2016

Academic Editor: Chris Goodrich

Copyright ( 2016 Jin Sha et al. This is an open access article distributed under the Creative Commons Attribution License, which permits unrestricted use, distribution, and reproduction in any medium, provided the original work is properly cited.

\begin{abstract}
Advertising is a crucial tool for demand creation and market expansion; enterprises in supply chain use it widely to increase sales and improve profits. But the homogeneity of products sold in hybrid channel supply chain magnifies the positive externalities of advertising and leads to serious free-riding problem. To coordinate the supply chain effectively, firstly, this paper classifies hybrid channel supply chain based on the relationship between members and selects horizontally integrated, vertically integrated, and decentralized hybrid channel supply chains as research objects. Then, a demand function considering the common effect of price and advertising is proposed and coordination schemes for different types of supply chains are designed. Finally, a sensitivity analysis is performed to assess the impact of parameters on coordination using orthogonal experiment.
\end{abstract}

\section{Introduction}

With the rapid development of electronic commerce and logistics industry, many manufacturers are increasingly changing their business strategy from single channel to hybrid channel. In hybrid channel supply chain, the same products are sold through both online and offline channels at the same time. This characteristic complicated the relationship between brick-and-mortar retailers and online retailers.

When the online channel is activated, the market demand that brick-and-mortar retailers face usually reduces and their benefits decrease significantly. In order to relieve the unfavorable situation, it is paramount for brick-and-mortar retailers to take countermeasures to increase channel demand and compete with online retailers. On the other hand, online retailers also take steps to improve their channel demand for the same purpose. For manufacturers, both offline and online channels are encouraged since the coopetition of hybrid channels improves the efficiency and competitiveness of the distribution channel which is beneficial to them, so they have motivation to make the effort to increase market demand too.

Advertising as the most common and economical marketing tool has the power of coverage extension, information transfer, demand stimulation, and sales increase.
Therefore, it has become the preferred means to improve respective market demand of brick-and-mortar retailers, online retailers, and manufacturers. However, advertising has strong positive externalities and leads to the emergence of free riding among supply chain members owing to the homogeneity of products sold in hybrid channel supply chain. Consumers are attracted by advertising and implement their purchasing behavior which incurs the increase of the total income of hybrid channel supply chain. But consumers are under no obligation to distinguish which channel retailer bears the costs of the advertising inducing their buying needs and then purchase products from the same channel to compensate the retailer's advertising costs. On the contrary, whichever supply chain member's advertisement triggers consumers' buying demand, consumers always choose the most convenient channel for them to close the deal. During this process, no retailer can guarantee that all consumption caused by his advertisement occurs only within his own channel. Hence, the retailers with no or less advertising costs could enjoy the sales growth and profit improvement due to other retailers' higher advertising investment. As a result, the retailers paying more advertising costs fail to gain the corresponding advertising benefits. Neither the extra costs of more advertising investment nor the undeserved extra 
return of less advertising investment could be embodied by market transaction. This makes advertising in hybrid channel supply chain possess the noncompetitive and nonexcludability features similar to public goods. This situation prompts the motivation of implementing free-riding strategy in advertising for the members of hybrid channel supply chain, discourages enterprise's sales effort, and has a serious negative impact on the overall benefit across the supply chain.

To tackle this problem, targeted coordination schemes in view of the different hybrid channel supply chain structure to help manufacturer, brick-and-mortar retailer, and online retailer are designed to solve the problem of free riding in advertising.

The rest of this paper is organized as follows. Section 2 provides a review of related literature. Section 3 clarifies the types of hybrid channel supply chain and proposes the channel demand function for further research. In Section 4 to Section 6, this paper establishes and analyzes the mathematical models aiming at horizontally integrated, vertically integrated, and decentralized hybrid channel supply chains, and then it develops coordination schemes considering advertising free-riding problem, respectively. Section 7 analyzes the sensitivity of supply chain parameters for coordination schemes using orthogonal experiment. Finally, conclusion remarks are given in Section 8.

\section{Literature Review}

As independent economic entities, supply chain participants choose decisions that maximize their own benefits. But the optimal strategy to a single member usually tends to cause the suboptimal results for the whole supply chain. In the absence of cooperation schemes, independent strategies of supply chain members may lead to whole chain inefficiency. In view of the important influence of advertising on market demand and enterprise profits, many researchers focus their research on how to give full play to advertising under the environment of supply chain.

To improve the efficiency of advertising in supply chain, many researchers [1-4] have contended that cooperative advertising in a partnership relationship between supply chain members can be very effective. Nagler [5] examined how participation rates vary with average manufacturers' margins by industry, average retail margins by category, and additional category-level variables through providing an exploratory empirical investigation for determining the cooperative advertising participation rates of the channel members. Chen [6] formulated both noncooperative and cooperative policies considering the combined effects of the cooperative advertising mechanism, returns policy, and vendor-buyer coordination based on newsvendor problem. His study revealed that the cooperative decision policy is always found to be superior to the noncooperative decision policy in profit improvement. He et al. [7] discussed the optimal strategy for retailers when the manufacturer shares or does not share the costs of advertising in a supply chain with one manufacturer and two retailers. Alaei et al. [8] discussed the case of how the manufacturer coordinates the channel in which two identical retailers compete on local advertising investment and researched the cooperative game in order to investigate the possibility of channel coordination and then proposed an advertising costs sharing contract to achieve perfect coordination of the channel. Castillo et al. [9] obtained the equilibrium strategies for a monopoly and a duopoly; the Cournot and Stackelberg cases and their analysis showed that an additive or multiplicative change in the unit price and the advertising expenditure would yield an additive or multiplicative change in sales. Krishnan and Jain [10] developed an empirically proven diffusion demand function that explicitly incorporates the advertising component and determined the optimal advertising expenditure by considering the advertising effectiveness, discount rate, and the ratio of advertisement to profits. Karray and Zaccour [11] studied a supply chain including two manufacturers and two retailers with national advertising efforts as exogenous parameters instead of decision variables. Szmerekovsky and Zhang [12] investigated a Stackelberg game in a decentralized system allowing for a continuous level of promotion efforts to be selected by both the manufacturer and the retailer and drew the conclusion that cost sharing of local advertising does not work well and that it is better for the manufacturer to advertise nationally and offer the retailer a lower wholesale price. Karray and Martín-Herrán [13] studied pricing and advertising competition between national and store brands. Yan [14] noted that retailers and manufacturers in dualchannel supply chain should take steps to enhance brand influence simultaneously and make up profit distribution plans for alleviating the conflict between channels. SeyedEsfahani et al. [15] analyzed manufacturer and retailer's strategy on pricing and advertising in four cases considering the influence of pricing and advertising. Kunter [16] investigated the channel coordination by applying cost and revenue sharing mechanism. Liu et al. [17] examined the efficacy of cost sharing in a model of two competing manufacturer-retailer supply chains and suggested that the firms performing the advertising would rather bear the costs entirely if this protects their unit profit margin. Sayadi and Makui [18] investigated dynamic brand and channel advertising and their effects on market expansion and market share in a dual-channel supply chain by using differential game theory and showed that higher compatibility of a product with online marketing leads to a higher advertising effort for the online channel by the manufacturer, an enhanced steady state for demand of the brand, and greater sales in the steady state through the online channel. Considering the effect of advertising investment to market demand, Hong et al. [19] built Stackelberg game models to investigate the optimal decisions of local advertising and used-product collection and pricing in centralized and decentralized closed-loop supply chains.

There are some literatures that raised doubts about cooperative advertising strategy; for example, He et al. [20] noted that manufacturer offering a co-op advertising program is not always an optimal strategy when the retailer's margin is significantly higher than the manufacturer's; Karray and Amin [21] developed a game-theoretic model and provided equilibrium solutions for two games considering both advertising and pricing as decision variables and obtained optimal solutions and then found that co-op advertising may not be profitable 


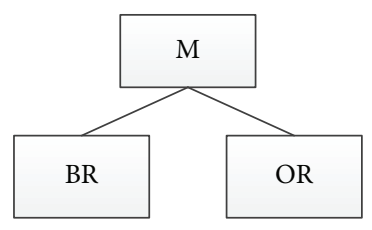

_ Integration relationship

(a) Integrated hybrid channel supply chain

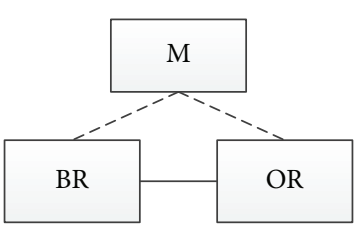

--- Independent relationship — Integration relationship

(b) Horizontally integrated hybrid channel supply chain

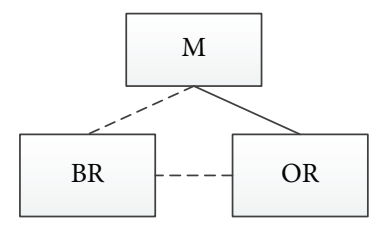

--- Independent relationship — Integration relationship

(c) Vertically integrated hybrid channel supply chain I

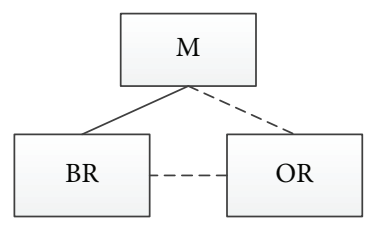

--- Independent relationship

— Integration relationship

(d) Vertically integrated hybrid channel supply chain II

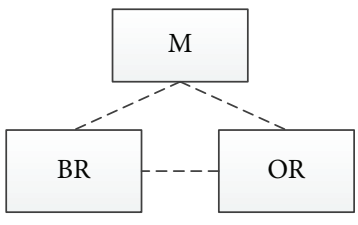

--- Independent relationship

(e) Decentralized hybrid channel supply chain

FIGURE 1: Five hybrid channel structures.

for the retailers or for the channel. Cooperative advertising is still an effective coordination mechanism for advertising activities in supply chain. In cooperative advertising, the manufacturers may contribute part of the advertising costs which are paid by retailers $[22,23]$, but the existing literatures rarely involved the study of advertising cost sharing in hybrid channel supply chain. Van Baal and Dach's research [24] showed that more than $20 \%$ of consumers are free riders, so this paper tries to establish reasonable advertising cost sharing mechanism for coordinating advertising free riding in hybrid channel supply chain.

\section{Preparation Work}

In this section, modeling preparation is completed. First, hybrid channel supply chain structures are summarized among which three structures are affected by advertising freeriding problem and hence are taken as the research objects. Then, modeling assumptions are described and parameters are set. Next, demand function considering the joint influence of channel prices and advertising for hybrid channel supply chain is chosen and established.

3.1. Selecting Research Objects. The hybrid channel supply chain which is studied by the vast majority of scholars is twoechelon supply chain composed of manufacturers and two channel retailers. According to the integration relationship among manufacturers, brick-and-mortar retailers, and online retailers and based on the research of Yoo and Lee [25], we can classify hybrid channel supply chain into five types, as shown in Figure 1. "M," "BR," and "OR" represent manufacturer, brick-and-mortar retailer, and online retailer, respectively.

Free-riding behavior must occur between economic agents with different interests, but, in integrated hybrid channel supply chain (type (a)), the manufacturer, brick-and-mortar retailer, and online retailer form a community of interests, so there is no free riding in it. In type (b), brick-and-mortar and online retailers implement integrated strategy but the manufacturer is not involved in it; the free-riding problem exists between the manufacturer and retailers. In vertically integrated hybrid channel supply chains I and II (types (c) and (d)), the manufacturer integrates downward online or offline retailer along the supply chain, which leads to free riding between the manufacturer and the retailer not being integrated. In type (e) (decentralized hybrid channel supply chain), there is free-riding problem among the three supply chain members.

Free riding exists in type (b) to type (e), but types (c) and (d) are similar in both structure and analytical approach, so we choose horizontally integrated, vertically integrated I (some scholars call it dual-channel), and decentralized hybrid channel supply chains as study objects to coordinate advertising free-riding problem.

3.2. Assumptions and Parameters Settings. We establish a hybrid channel supply chain model with a single manufacturer and two retailers (online and offline); there is only one product being sold. The manufacturer determines the wholesale price first; then, different channels retailers determine their retail price simultaneously. Every supply chain participant pays for advertising to increase market demand and the total advertising costs are known. Suppose $d$ is channel demand, $a$ is the potential market demand, and $\rho$ is the market share of online channel $(0<\rho<1)$. $p$ is sales price, $\omega$ is wholesale price, $\pi$ is revenue, $\alpha$ is the direct price impact factor of channel $(\alpha>0)$, and $\beta$ is the cross price impact factor between channels $(\beta>0)$. The parameter $\rho$ reflects the consumer preference for online channel, and $\alpha$ and $\beta$ reflect the influence of price change on demand. The three parameters depend on the characteristics of consumers 
and supply chain agents cannot control them, so $\rho, \alpha$, and $\beta$ are all exogenous. Because the change of one channel price has greater influence on the demand of its own channel than on the demand of the other channel and one channel price impacts its own channel demand more greatly than what the other channel price impacts, we consider $\alpha>\beta$. Let subscripts $m, r$, and $e$ mark the parameters of manufacturer, brick-and-mortar retailer, and online retailer.

3.3. Demand Function Construction. There are two commonly used demand functions in the area of hybrid channel supply chain. One is mentioned in Yue and Liu's paper [26]:

$$
\begin{aligned}
& d_{r}=(1-\rho) a-\alpha_{r} p_{r}+\beta_{r} p_{e} \\
& d_{e}=\rho a-\alpha_{e} p_{e}+\beta_{e} p_{r} .
\end{aligned}
$$

The other is presented by Ingene and Parry [27]:

$$
U=\sum_{i=r, e}\left(a_{i} d_{i}-\frac{b d_{i}^{2}}{2}\right)-\theta d_{r} d_{e}-\sum_{i=r, e} p_{i} d_{i} .
$$

Here, $U$ is consumer utility function, $b$ is the change rate of channel marginal utility, and $\theta$ is the channel substitution rate $(0<\theta<1)$. Maximizing $U$, we can get the channel demand function:

$$
\begin{aligned}
& d_{r}=\frac{b a_{r}-\theta a_{e}-b p_{r}+\theta p_{e}}{b^{2}-\theta^{2}}, \\
& d_{e}=\frac{b a_{e}-\theta a_{r}-b p_{e}+\theta p_{r}}{b^{2}-\theta^{2}} .
\end{aligned}
$$

Although the second demand function has been widely used, the relationship between advertising and consumer utility is still unclear. So this paper selects formula (1) as the prototype of demand function. In order to reflect the market demand affected by both pricing and advertising efforts simultaneously, based on Yao and Liu [28], we formulate the hybrid channel supply chain demand function considering advertising as

$$
\begin{aligned}
& d_{r}^{\prime}=(1-\rho) a-\alpha_{r} p_{r}^{\prime}+\beta_{r} p_{e}^{\prime}+k_{r} \sqrt{t} \\
& d_{e}^{\prime}=\rho a-\alpha_{e} p_{e}^{\prime}+\beta_{e} p_{r}^{\prime}+k_{e} \sqrt{t}
\end{aligned}
$$

Superscript " $\rho$ " means the parameters with free riding, $k$ is the impact factor of advertising, and $t$ is the total advertising costs of the supply chain. For reflecting the diminishing marginal return of advertising, we use $\sqrt{t}$ to embody the advertising effect.

\section{Coordination in Horizontally Integrated Hybrid Channel Supply Chain}

In horizontally integrated hybrid channel supply chain, the manufacturer advertises his product offline and online retailers also pay for their advertising together. There is free riding between manufacturer and retailer alliance. Because of the integration of two channel retailers, manufacturers can only charge both retailers at the same wholesale price, but different channel retailer can charge customers at different retail price.
4.1. Modeling and Analysis. Based on formula (4), under the condition of advertising, the profits of manufacturer and retailer alliance can be represented as

$$
\begin{aligned}
\pi_{m}^{\prime} & =\omega^{\prime}\left(d_{r}^{\prime}+d_{e}^{\prime}\right)-\varphi_{m} t \\
\pi_{r}^{\prime}+\pi_{e}^{\prime} & =\left(p_{r}^{\prime}-\omega^{\prime}\right) d_{r}^{\prime}+\left(p_{e}^{\prime}-\omega^{\prime}\right) d_{e}^{\prime}-\left(1-\varphi_{m}\right) t .
\end{aligned}
$$

Here, $\varphi$ is the advertising cost sharing proportion.

Because the manufacturer can determine the product wholesale price, it is the advantage of the game. According to Stackelberg game rule, we can deduce the optimal decision of supply chain members using backward induction.

Substitute formula (4) into (6) and then calculate its Hessian matrix about $p_{r}^{\prime}, p_{e}^{\prime}$, and $\sqrt{t}$ :

$$
H=\left[\begin{array}{ccc}
-2 \alpha_{r} & \beta_{r}+\beta_{e} & k_{r} \\
\beta_{r}+\beta_{e} & -2 \alpha_{e} & k_{e} \\
k_{r} & k_{e} & -2\left(1-\varphi_{m}\right)
\end{array}\right] .
$$

From formula (7), when $\alpha>\beta, \pi_{r}^{\prime}+\pi_{e}^{\prime}$ is a joint strictly concave function about $p_{r}^{\prime}$ and $p_{e}^{\prime}$, but it is not a joint concave function about $p_{r}^{\prime}, p_{e}^{\prime}$, and $\sqrt{t}$, so we cannot use first-order optimality condition to get the manufacturer's optimal strategy. Nevertheless, the purpose of this paper is to eliminate free-riding behavior in advertising of hybrid channel supply chain and there is no need to determine the optimal advertising cost, so we can solve this problem by using two-phase optimization technique as follows. First, assume that $\sqrt{t}$ is known and calculate the optimal channel prices of retailer alliance. Then, use formula (5) to get manufacturer's optimal wholesale price expressed by $\sqrt{t}$.

Maximize (6) and solve the following equations:

$$
\begin{aligned}
& \frac{\partial\left(\pi_{r}^{\prime}+\pi_{e}^{\prime}\right)}{\partial p_{r}^{\prime}}=0, \\
& \frac{\partial\left(\pi_{r}^{\prime}+\pi_{e}^{\prime}\right)}{\partial p_{e}^{\prime}}=0 .
\end{aligned}
$$

We can get $p_{r}^{\prime *}$ and $p_{e}^{\prime *}$ and then substitute them into (5) and solve equation $\partial \pi_{m}^{\prime} / \partial \omega^{\prime}=0$ to get $\omega_{m}^{\prime *}$ :

$$
\begin{aligned}
\omega^{\prime *} & =\left(\left(4 \alpha_{r} \alpha_{e}-\left(\beta_{r}+\beta_{e}\right)^{2}\right) a-\left(2 \alpha_{r} \alpha_{e}+\alpha_{e} \beta_{r}-\alpha_{e} \beta_{e}\right.\right. \\
& \left.-\beta_{r} \beta_{e}-\beta_{r}^{2}\right)(1-\rho) a-\left(2 \alpha_{r} \alpha_{e}-\alpha_{r} \beta_{r}+\alpha_{r} \beta_{e}\right. \\
& \left.-\beta_{r} \beta_{e}-\beta_{e}^{2}\right) \rho a \\
& +\left(\left(2 \alpha_{r} \alpha_{e}-\alpha_{e} \beta_{r}+\alpha_{e} \beta_{e}-\beta_{r} \beta_{e}-\beta_{e}^{2}\right) k_{r}\right. \\
& \left.\left.+\left(2 \alpha_{r} \alpha_{e}+\alpha_{r} \beta_{r}-\alpha_{r} \beta_{e}-\beta_{r} \beta_{e}-\beta_{r}^{2}\right) k_{e}\right) \sqrt{t}\right) \\
& \cdot\left(4\left(\alpha_{r} \alpha_{e}-\beta_{r} \beta_{e}\right)\left(\alpha_{r}+\alpha_{e}-\beta_{r}-\beta_{e}\right)\right)^{-1}
\end{aligned}
$$


Then, we get

$$
\begin{aligned}
& p_{r}^{\prime *}=\left(4 ( \alpha _ { r } \alpha _ { e } - \beta _ { r } \beta _ { e } ) ( \alpha _ { r } + \alpha _ { e } - \beta _ { r } - \beta _ { e } ) \left(2 \alpha_{e}(1\right.\right. \\
& \left.-\rho) a+\left(\beta_{r}+\beta_{e}\right) \rho a\right)+\left(2 \alpha_{r} \alpha_{e}+\alpha_{e} \beta_{r}-\alpha_{e} \beta_{e}\right. \\
& \left.-\beta_{r} \beta_{e}-\beta_{r}^{2}\right)\left(\left(4 \alpha_{r} \alpha_{e}-\left(\beta_{r}+\beta_{e}\right)^{2}\right) a-\left(2 \alpha_{r} \alpha_{e}\right.\right. \\
& \left.+\alpha_{e} \beta_{r}-\alpha_{e} \beta_{e}-\beta_{r} \beta_{e}-\beta_{r}^{2}\right)(1-\rho) a-\left(2 \alpha_{r} \alpha_{e}\right. \\
& \left.\left.-\alpha_{r} \beta_{r}+\alpha_{r} \beta_{e}-\beta_{r} \beta_{e}-\beta_{e}^{2}\right) \rho a\right)+\left(\left(2 \alpha_{r} \alpha_{e}+\alpha_{e} \beta_{r}\right.\right. \\
& \left.-\alpha_{e} \beta_{e}-\beta_{r} \beta_{e}-\beta_{r}^{2}\right) \\
& \cdot\left(\left(2 \alpha_{r} \alpha_{e}-\alpha_{e} \beta_{r}+\alpha_{e} \beta_{e}-\beta_{r} \beta_{e}-\beta_{e}^{2}\right) k_{r}\right. \\
& \left.+\left(2 \alpha_{r} \alpha_{e}+\alpha_{r} \beta_{r}-\alpha_{r} \beta_{e}-\beta_{r} \beta_{e}-\beta_{r}^{2}\right) k_{e}\right)+4\left(\alpha_{r} \alpha_{e}\right. \\
& \left.\left.-\beta_{r} \beta_{e}\right)\left(\alpha_{r}+\alpha_{e}-\beta_{r}-\beta_{e}\right)\left(2 \alpha_{e} k_{r}+\left(\beta_{r}+\beta_{e}\right) k_{e}\right)\right) \\
& \cdot \sqrt{t})\left(4 ( 4 \alpha _ { r } \alpha _ { e } - ( \beta _ { r } + \beta _ { e } ) ^ { 2 } ) ( \alpha _ { r } \alpha _ { e } - \beta _ { r } \beta _ { e } ) \left(\alpha_{r}\right.\right. \\
& \left.\left.+\alpha_{e}-\beta_{r}-\beta_{e}\right)\right)^{-1} \text {, } \\
& p_{e}^{\prime *}=\left(4 ( \alpha _ { r } \alpha _ { e } - \beta _ { r } \beta _ { e } ) ( \alpha _ { r } + \alpha _ { e } - \beta _ { r } - \beta _ { e } ) \left(\left(\beta_{r}+\beta_{e}\right)\right.\right. \\
& \left.\cdot(1-\rho) a+2 \alpha_{r} \rho a\right)+\left(2 \alpha_{r} \alpha_{e}-\alpha_{r} \beta_{r}+\alpha_{r} \beta_{e}\right. \\
& \left.-\beta_{r} \beta_{e}-\beta_{e}^{2}\right)\left(\left(4 \alpha_{r} \alpha_{e}-\left(\beta_{r}+\beta_{e}\right)^{2}\right) a-\left(2 \alpha_{r} \alpha_{e}\right.\right. \\
& \left.+\alpha_{e} \beta_{r}-\alpha_{e} \beta_{e}-\beta_{r} \beta_{e}-\beta_{r}^{2}\right)(1-\rho) a-\left(2 \alpha_{r} \alpha_{e}\right. \\
& \left.\left.-\alpha_{r} \beta_{r}+\alpha_{r} \beta_{e}-\beta_{r} \beta_{e}-\beta_{e}^{2}\right) \rho a\right)+\left(\left(2 \alpha_{r} \alpha_{e}-\alpha_{r} \beta_{r}\right.\right. \\
& \left.+\alpha_{r} \beta_{e}-\beta_{r} \beta_{e}-\beta_{e}^{2}\right) \\
& \cdot\left(\left(2 \alpha_{r} \alpha_{e}-\alpha_{e} \beta_{r}+\alpha_{e} \beta_{e}-\beta_{r} \beta_{e}-\beta_{e}^{2}\right) k_{r}\right. \\
& \left.+\left(2 \alpha_{r} \alpha_{e}+\alpha_{r} \beta_{r}-\alpha_{r} \beta_{e}-\beta_{r} \beta_{e}-\beta_{r}^{2}\right) k_{e}\right)+4\left(\alpha_{r} \alpha_{e}\right. \\
& \left.\left.-\beta_{r} \beta_{e}\right)\left(\alpha_{r}+\alpha_{e}-\beta_{r}-\beta_{e}\right)\left(\left(\beta_{r}+\beta_{e}\right) k_{r}+2 \alpha_{r} k_{e}\right)\right) \\
& \cdot \sqrt{t})\left(4 ( 4 \alpha _ { r } \alpha _ { e } - ( \beta _ { r } + \beta _ { e } ) ^ { 2 } ) ( \alpha _ { r } \alpha _ { e } - \beta _ { r } \beta _ { e } ) \left(\alpha_{r}\right.\right. \\
& \left.\left.+\alpha_{e}-\beta_{r}-\beta_{e}\right)\right)^{-1} \text {. }
\end{aligned}
$$

Formulae (9) and (10) show that advertising cost sharing proportion $\varphi$ has no effect on the optimal prices of manufacturer and retailers. Once the total advertising cost $t$ is determined, the optimal prices of supply chain members are determined too. The parameter $\varphi$ affects the profits of enterprises only. To facilitate the description, suppose

$$
\begin{aligned}
& \omega^{\prime *}=(H+J \sqrt{t}) R^{-1}, \\
& p_{r}^{\prime *}=(L+M \sqrt{t})(R S)^{-1}, \\
& p_{e}^{\prime *}=(N+Q \sqrt{t})(R S)^{-1} .
\end{aligned}
$$

4.2. Coordination. The purpose of advertising investment is to enhance market demand and improve enterprise profits, so the advertising costs will be proportional to the revenue produced by it. For coordinating free-riding problem in hybrid channel supply chain advertising, we must make advertising costs and benefits associate with each other, so we select "benefit principle" as foundation. Benefit principle shares the costs based on the revenue; we get advertising costs allocation proportion formula according to it:

$$
\varphi_{i}=\frac{\Delta \pi_{i}}{\sum_{i=m, r, e} \Delta \pi_{i}},
$$

where

$$
\Delta \pi_{i}=\pi_{i}^{\prime}-\pi_{i} .
$$

In horizontally integrated hybrid channel supply chain, the optimal decisions of manufacturer and retailers without advertising are

$$
\begin{aligned}
& \omega^{*}=H R^{-1}, \\
& p_{r}^{*}=L(R S)^{-1}, \\
& p_{e}^{*}=N(R S)^{-1} .
\end{aligned}
$$

Substitute (11) and (14) into (5) and (6) and then into (12) and (13); we can get that the advertising costs proportion that the manufacturer will share is

$$
\begin{aligned}
\varphi_{m} & =\left(S \left(J R S a-\left(\alpha_{r}-\beta_{e}\right)(H M+J L)\right.\right. \\
& \left.-\left(\alpha_{e}-\beta_{r}\right)(H Q+J N)+H R S\left(k_{r}+k_{e}\right)\right) \\
& \left.-J S\left(M\left(\alpha_{r}-\beta_{e}\right)+Q\left(\alpha_{e}-\beta_{r}\right)-R S\right) \sqrt{t}\right) \\
& \cdot\left(R S\left(M(1-\rho) a+Q \rho a+L k_{r}+N k_{e}\right)\right. \\
& -2\left(L M \alpha_{r}+N Q \alpha_{e}\right)+(L Q+M N)\left(\beta_{r}+\beta_{e}\right) \\
& -\left(M^{2} \alpha_{r}+Q^{2} \alpha_{e}-M Q\left(\beta_{r}+\beta_{e}\right)\right. \\
& \left.\left.-R S\left(M k_{r}+Q k_{e}\right)\right) \sqrt{t}\right)^{-1} .
\end{aligned}
$$

The retailers will share $1-\varphi_{m}$.

\section{Coordination in Dual-Channel Supply Chain}

In dual-channel supply chain, the manufacturer and brickand-mortar retailer pay for their advertising separately, so free riding exists between them. Manufacturer determines the wholesale price and online channel price firstly, and then brick-and-mortar retailer confirms his channel price.

5.1. Modeling and Analysis. With advertising, the profits of manufacturer and brick-and-mortar retailer are

$$
\begin{aligned}
\pi_{m}^{\prime} & =p_{e}^{\prime} d_{e}^{\prime}+\omega^{\prime} d_{r}^{\prime}-\left(1-\varphi_{r}\right) t, \\
\pi_{r}^{\prime} & =\left(p_{r}^{\prime}-\omega^{\prime}\right) d_{r}^{\prime}-\varphi_{r} t .
\end{aligned}
$$


According to backward induction, let $\partial \pi_{r}^{\prime} / \partial p_{r}^{\prime}=0$; get

$$
p_{r}^{\prime}=\frac{(1-\rho) a+\beta_{r} p_{e}^{\prime}+\alpha_{r} \omega^{\prime}+k_{r} \sqrt{t}}{2 \alpha_{r}} .
$$

Substitute (18) into (16) and calculate its Hessian matrix about $p_{e}^{\prime}, \omega^{\prime}$, and $\sqrt{t}$ :

$$
H=\left[\begin{array}{ccc}
\frac{-2 \alpha_{r} \alpha_{e}+\beta_{r} \beta_{e}}{\alpha_{r}} & \frac{\beta_{r}+\beta_{e}}{2} & \frac{\beta_{e} k_{r}+2 \alpha_{r} k_{e}}{2 \alpha_{r}} \\
\frac{\beta_{r}+\beta_{e}}{2} & -\alpha_{r} & \frac{k_{r}}{2} \\
\frac{\beta_{e} k_{r}+2 \alpha_{r} k_{e}}{2 \alpha_{r}} & \frac{k_{r}}{2} & -2\left(1-\varphi_{r}\right)
\end{array}\right] .
$$

When $\alpha>\beta$ and from formula (19), $\pi_{m}^{\prime}$ is a joint strictly concave function about $p_{e}^{\prime}$ and $\omega^{\prime}$, but it is not a joint concave function about $p_{e}^{\prime}, \omega^{\prime}$, and $\sqrt{t}$. For the same reason mentioned in Section 4.1, solve the following equations:

$$
\begin{aligned}
& p_{e}^{\prime *}=\frac{4 \alpha_{r} \rho a+\left(\beta_{r}+3 \beta_{e}\right)(1-\rho) a+\left(\beta_{r}+3 \beta_{e}\right) k_{r} \sqrt{t}+4 \alpha_{r} k_{e} \sqrt{t}}{8 \alpha_{r} \alpha_{e}-6 \beta_{r} \beta_{e}-\beta_{r}^{2}-\beta_{e}^{2}}, \\
& \omega^{\prime *}=\frac{2 \alpha_{r}\left(\beta_{r}+\beta_{e}\right) \rho a+\left(4 \alpha_{r} \alpha_{e}-\beta_{r} \beta_{e}+\beta_{e}^{2}\right)(1-\rho) a+\left(4 \alpha_{r} \alpha_{e}-\beta_{r} \beta_{e}+\beta_{e}^{2}\right) k_{r} \sqrt{t}+2 \alpha_{r}\left(\beta_{r}+\beta_{e}\right) k_{e} \sqrt{t}}{\left(8 \alpha_{r} \alpha_{e}-6 \beta_{r} \beta_{e}-\beta_{r}^{2}-\beta_{e}^{2}\right) \alpha_{r}} .
\end{aligned}
$$

Get

Substituting (21) into (18), the following can be gotten:

$$
p_{r}^{\prime *}=\frac{\alpha_{r}\left(3 \beta_{r}+\beta_{e}\right) \rho a+\left(6 \alpha_{r} \alpha_{e}-2 \beta_{r} \beta_{e}\right)(1-\rho) a+\left(6 \alpha_{r} \alpha_{e}-2 \beta_{r} \beta_{e}\right) k_{r} \sqrt{t}+\alpha_{r}\left(3 \beta_{r}+\beta_{e}\right) k_{e} \sqrt{t}}{\left(8 \alpha_{r} \alpha_{e}-6 \beta_{r} \beta_{e}-\beta_{r}^{2}-\beta_{e}^{2}\right) \alpha_{r}} .
$$

5.2. Coordination. For convenient expression, suppose

$$
\begin{aligned}
& p_{r}^{\prime *}=\frac{A+B \sqrt{t}}{G \alpha_{r}}, \\
& p_{e}^{\prime *}=\frac{C+D \sqrt{t}}{G}, \\
& \omega^{\prime *}=\frac{E+F \sqrt{t}}{G \alpha_{r}} .
\end{aligned}
$$

So,

$$
\begin{aligned}
p_{r}^{*} & =\frac{A}{G \alpha_{r}}, \\
p_{e}^{*} & =\frac{C}{G}, \\
\omega^{*} & =\frac{E}{G \alpha_{r}} .
\end{aligned}
$$

Substitute (23) and (24) into (16) and (17) and then into (12) and (13); we can get that the advertising costs proportion that the brick-and-mortar retailer will share is

$$
\begin{aligned}
\varphi_{r} & =((B-F) G(1-\rho) a+A F+B E-2 A B+(A D \\
& -D E+B C-C F) \beta_{r}+(A G-E G) k_{r} \\
& \left.+\left((B-F)\left(D \beta_{r}+G k_{r}\right)-B^{2}\right) \sqrt{t}\right)(B G(1-\rho) a \\
& +D G \alpha_{r} \rho a-2 A B+(A D+B C)\left(\beta_{r}+\beta_{e}\right)+A G k_{r} \\
& -2 C D \alpha_{r} \alpha_{e}+C G \alpha_{r} k_{e}+\left(B D\left(\beta_{r}+\beta_{e}\right)\right. \\
& \left.\left.+B\left(G k_{r}-B\right)+D \alpha_{r}\left(G k_{e}-D \alpha_{e}\right)\right) \sqrt{t}\right)^{-1} .
\end{aligned}
$$

The manufacturer will share $1-\varphi_{r}$.

\section{Coordination in Decentralized Hybrid Channel Supply Chain}

Manufacturer, brick-and-mortar retailer, and online retailer are all individual with independent decision in decentralized hybrid channel supply chain. Manufacturer charges different channel retailers for different wholesale price, and then the two channel retailers determine respective price simultaneously. 
6.1. Modeling and Analysis. The supply chain members' profits are

$$
\begin{aligned}
& \pi_{m}^{\prime}=\omega_{r}^{\prime} d_{r}^{\prime}+\omega_{e}^{\prime} d_{e}^{\prime}-\varphi_{m} t, \\
& \pi_{r}^{\prime}=\left(p_{r}^{\prime}-\omega_{r}^{\prime}\right) d_{r}^{\prime}-\varphi_{r} t \\
& \pi_{e}^{\prime}=\left(p_{e}^{\prime}-\omega_{e}^{\prime}\right) d_{e}^{\prime}-\varphi_{e} t .
\end{aligned}
$$

Solve the equations

$$
\begin{aligned}
& \frac{\partial \pi_{r}^{\prime}}{\partial p_{r}^{\prime}}=0 \\
& \frac{\partial \pi_{e}^{\prime}}{\partial p_{e}^{\prime}}=0 .
\end{aligned}
$$

We can get

$$
\begin{aligned}
& p_{r}^{\prime *}=\frac{2 \alpha_{e}(1-\rho) a+\beta_{r} \rho a+\alpha_{e} \beta_{r} \omega_{e}^{\prime}+2 \alpha_{r} \alpha_{e} \omega_{r}^{\prime}+\beta_{r} k_{e} \sqrt{t}+2 \alpha_{e} k_{r} \sqrt{t}}{4 \alpha_{r} \alpha_{e}-\beta_{r} \beta_{e}}, \\
& p_{e}^{\prime *}=\frac{2 \alpha_{r} \rho a+\beta_{e}(1-\rho) a+\alpha_{r} \beta_{e} \omega_{r}^{\prime}+2 \alpha_{r} \alpha_{e} \omega_{e}^{\prime}+\beta_{e} k_{r} \sqrt{t}+2 \alpha_{r} k_{e} \sqrt{t}}{4 \alpha_{r} \alpha_{e}-\beta_{r} \beta_{e}} .
\end{aligned}
$$

Substitute (30) and (31) into (26) and calculate its Hessian matrix about $\omega_{r}^{\prime}$ and $\omega_{e}^{\prime}$ :

$$
H=\left[\begin{array}{cc}
\frac{2 \alpha_{r} \beta_{r} \beta_{e}-4 \alpha_{r}^{2} \alpha_{e}}{4 \alpha_{r} \alpha_{e}-\beta_{r} \beta_{e}} & \frac{\alpha_{r} \alpha_{e}\left(\beta_{r}+\beta_{e}\right)}{4 \alpha_{r} \alpha_{e}-\beta_{r} \beta_{e}} \\
\frac{\alpha_{r} \alpha_{e}\left(\beta_{r}+\beta_{e}\right)}{4 \alpha_{r} \alpha_{e}-\beta_{r} \beta_{e}} & \frac{2 \alpha_{e} \beta_{r} \beta_{e}-4 \alpha_{r} \alpha_{e}^{2}}{4 \alpha_{r} \alpha_{e}-\beta_{r} \beta_{e}}
\end{array}\right] .
$$

With the constraint condition of $\alpha>\beta$, we cannot ensure that formula (32) must be negative definite, so we cannot find out the optimal $\omega_{r}^{\prime}$ and $\omega_{e}^{\prime}$ maximizing manufacturer's profits; the coordination approach of advertising cost sharing used in Sections 4 and 5 is not suitable to deal with advertising free riding in decentralized hybrid channel supply chain. But we can utilize the advantage position of manufacturer and adjust channel wholesale prices to coordinate supply chain completely.

6.2. Coordination. To perform complete coordination, we analyze integrated hybrid channel supply chain (type (a)) firstly. In the case of integration, the profit of supply chain is

$$
\pi^{\prime}=p_{r}^{\prime} d_{r}^{\prime}+p_{e}^{\prime} d_{e}^{\prime}-t
$$

We can find out that the optimal pricing strategy is

$$
\begin{aligned}
& p_{r}^{*} \\
& \quad=\frac{2 \alpha_{e}\left((1-\rho) a+k_{r} \sqrt{t}\right)+\left(\beta_{r}+\beta_{e}\right)\left(\rho a+k_{e} \sqrt{t}\right)}{4 \alpha_{r} \alpha_{e}-\left(\beta_{r}+\beta_{e}\right)^{2}}, \\
& p_{e}^{*} \\
& =\frac{\left(\beta_{r}+\beta_{e}\right)\left((1-\rho) a+k_{r} \sqrt{t}\right)+2 \alpha_{r}\left(\rho a+k_{e} \sqrt{t}\right)}{4 \alpha_{r} \alpha_{e}-\left(\beta_{r}+\beta_{e}\right)^{2}} .
\end{aligned}
$$

The integrated supply chain can generate the most whole revenues in all types, so we make formulae (30) and (31) equal to (34) and (35), respectively, and then get

$$
\begin{aligned}
& \omega_{r}^{\prime *} \\
& =\frac{\beta_{e}\left(\left(\beta_{r}+\beta_{e}\right)\left((1-\rho) a+k_{r} \sqrt{t}\right)+2 \alpha_{r}\left(\rho a+k_{e} \sqrt{t}\right)\right)}{\alpha_{r}\left(4 \alpha_{r} \alpha_{e}-\left(\beta_{r}+\beta_{e}\right)^{2}\right)}, \\
& \omega_{e}^{\prime *} \\
& =\frac{\beta_{r}\left(2 \alpha_{e}\left((1-\rho) a+k_{r} \sqrt{t}\right)+\left(\beta_{r}+\beta_{e}\right)\left(\rho a+k_{e} \sqrt{t}\right)\right)}{\alpha_{e}\left(4 \alpha_{r} \alpha_{e}-\left(\beta_{r}+\beta_{e}\right)^{2}\right)} .
\end{aligned}
$$

If manufacturer determines the wholesale price of each channel according to (36), brick-and-mortar and online retailers will make their retail prices equal to the optimal prices; then, the supply chain will achieve the coordination completely.

\section{Sensitivity Analysis}

From the above analysis results, coordination schemes of advertising free riding are affected by nine parameters; in order to carry out sensitivity analysis more easily, we choose the orthogonal experiment for numerical analysis. Assume every parameter has two levels: high and low, and the high level is more than the low by $20 \%$; choose $\mathrm{L}_{12}\left(2^{11}\right)$ orthogonal table to analyze. Table 1 shows the experimental results of formulae (15), (25), and (36).

With Table 1, we can find out that, in horizontally integrated hybrid channel supply chain, each parameter's importance of affecting advertising cost sharing proportion follows this order: $\beta_{r}, k_{e}, t, a, \alpha_{e}, k_{r}, \rho, \alpha_{r}, \beta_{e}$. In dualchannel supply chain, this order is $\beta_{e}, \beta_{r}, \alpha_{e}, \rho, k_{r}, k_{e}, \alpha_{r}, a, t$. In decentralized hybrid channel supply chain, the importance of each parameter for affecting offline channel wholesale price is in turn $\alpha_{e}, \beta_{e}, \alpha_{r}, \beta_{r}, t, k_{r}, k_{e}, \rho, a$ and for affecting online channel is $\alpha_{e}, \beta_{r}, \alpha_{r}, \beta_{e}, t, k_{r}, a, \rho, k_{e}$. 
TABLE 1: Numerical analysis orthogonal table.

\begin{tabular}{lcccccccccccccc}
\hline Serial number & $\rho$ & $a$ & $\alpha_{r}$ & $\alpha_{e}$ & $\beta_{r}$ & $\beta_{e}$ & $k_{r}$ & $k_{e}$ & $t$ & $\varphi_{m}$ & $\varphi_{r}$ & $\omega_{r}^{\prime *}$ & $\omega_{e}^{\prime *}$ \\
\hline 1 & 0.5 & 100 & 0.5 & 0.5 & 0.4 & 0.4 & 0.25 & 0.25 & 500 & $66.67 \%$ & $2.56 \%$ & 222.36 & 222.36 \\
2 & 0.5 & 100 & 0.5 & 0.5 & 0.4 & 0.48 & 0.3 & 0.3 & 600 & $64.53 \%$ & $0.16 \%$ & 458.79 & 382.32 \\
3 & 0.5 & 100 & 0.6 & 0.6 & 0.48 & 0.4 & 0.25 & 0.25 & 600 & $65.82 \%$ & $5.44 \%$ & 116.92 & 140.31 \\
4 & 0.5 & 120 & 0.5 & 0.6 & 0.48 & 0.4 & 0.3 & 0.3 & 500 & $60.89 \%$ & $5.10 \%$ & 235.74 & 260.81 \\
5 & 0.5 & 120 & 0.6 & 0.5 & 0.48 & 0.48 & 0.25 & 0.3 & 600 & $63.23 \%$ & $1.28 \%$ & 414.65 & 450.96 \\
6 & 0.5 & 120 & 0.6 & 0.6 & 0.4 & 0.48 & 0.3 & 0.25 & 500 & $66.14 \%$ & $2.15 \%$ & 165.16 & 137.99 \\
7 & 0.6 & 100 & 0.6 & 0.6 & 0.4 & 0.4 & 0.3 & 0.3 & 600 & $66.67 \%$ & $3.51 \%$ & 98.91 & 92.25 \\
8 & 0.6 & 100 & 0.6 & 0.5 & 0.48 & 0.48 & 0.3 & 0.25 & 500 & $62.92 \%$ & $1.27 \%$ & 355.02 & 378.19 \\
9 & 0.6 & 100 & 0.5 & 0.6 & 0.48 & 0.48 & 0.25 & 0.3 & 500 & $64.70 \%$ & $1.27 \%$ & 380.95 & 341.23 \\
10 & 0.6 & 120 & 0.6 & 0.5 & 0.4 & 0.4 & 0.25 & 0.3 & 500 & $63.61 \%$ & $2.26 \%$ & 163.48 & 166.51 \\
11 & 0.6 & 120 & 0.5 & 0.6 & 0.4 & 0.48 & 0.25 & 0.25 & 600 & $66.76 \%$ & $0.79 \%$ & 283.65 & 209.43 \\
12 & 0.6 & 120 & 0.5 & 0.5 & 0.48 & 0.4 & 0.3 & 0.25 & 600 & $64.66 \%$ & $3.97 \%$ & 449.75 & 528.07 \\
$R \varphi_{m}$ & $0.34 \%$ & $1.00 \%$ & $0.03 \%$ & $0.89 \%$ & $2.02 \%$ & $0.01 \%$ & $0.83 \%$ & $1.56 \%$ & $1.12 \%$ & & & \\
$R \varphi_{r}$ & $0.61 \%$ & $0.22 \%$ & $0.34 \%$ & $1.13 \%$ & $1.15 \%$ & $2.65 \%$ & $0.43 \%$ & $0.43 \%$ & $0.09 \%$ & & & \\
$R \omega_{r}$ & 19.69 & 13.24 & 119.52 & 130.45 & 93.45 & 128.51 & 30.23 & 26.61 & 50.00 & & & \\
$R \omega_{e}$ & 20.15 & 32.85 & 96.34 & 157.73 & 148.12 & 81.63 & 41.47 & 12.96 & 49.37 & & & \\
\hline
\end{tabular}

\section{Conclusions}

In this paper, we elaborate the free-riding problem in hybrid channel supply chain caused by positive externalities of advertising and analyze its negative effects on supply chain. To tackle this problem, classify hybrid channel supply chain into five types on the basis of whether there is advertising free rider among members and choose horizontally integrated, dual-channel, and decentralized supply chain as study objects to establish demand function considering the effects of channel prices and advertising and then design coordination scheme for each type.

We show that manufacturer and retailer can share the advertising cost reasonably by using "income principle" so as to eliminate advertising free riding effectively in horizontally integrated and dual-channel supply chain. Manufacturer can adjust the wholesale prices to coordinate decentralized hybrid channel supply chain completely. Then, we obtain the precise formulas of advertising cost sharing proportion and optimal wholesale prices. At the end of our paper, we use orthogonal experiment to perform sensitivity analysis and make the sequences of importance of difference parameters affecting the coordination schemes.

However, there are still some limitations in this paper. We aim to obtain the optimal advertising cost sharing proportion so we do not answer the question of what the optimal advertising cost is for each supply chain member. Our study can be extended to research the optimal advertising cost in hybrid channel supply chain.

\section{Competing Interests}

The authors declare solemnly that there are no competing interests regarding the publication of this paper.

\section{Acknowledgments}

This paper is supported by the 2011 Funded Project of the National Natural Science Foundation of China (71171084).

\section{References}

[1] P. D. Berger, "Vertical cooperative advertising ventures," Journal of Marketing Research, vol. 9, no. 3, pp. 309-312, 1972.

[2] R. P. Dant and P. D. Berger, "Modelling cooperative advertising decisions in franchising," Journal of the Operational Research Society, vol. 47, no. 9, pp. 1120-1136, 1996.

[3] S. Dutta, M. E. Bergen, G. John, and A. R. Rao, "Variations in the contractual terms of cooperative advertising contracts: an empirical investigation," Marketing Letters, vol. 6, no. 1, pp. 1522, 1995.

[4] T. M. Somers, Y. P. Gupta, and S. R. Herriott, "Analysis of cooperative advertising expenditures: a transfer-function modeling approach," Journal of Advertising Research, vol. 30, pp. 35-45, 1990.

[5] M. G. Nagler, "An exploratory analysis of the determinants of cooperative advertising participation rates," Marketing Letters, vol. 17, no. 2, pp. 91-102, 2006.

[6] T.-H. Chen, "Coordinating the ordering and advertising policies for a single-period commodity in a two-level supply chain," Computers and Industrial Engineering, vol. 61, no. 4, pp. 12681274, 2011.

[7] X.-L. He, A. Krishnamoorthy, A. Prasad, and S. P. Sethi, "Retail competition and cooperative advertising," Operations Research Letters, vol. 39, no. 1, pp. 11-16, 2011.

[8] S. Alaei, R. Alaei, and P. Salimi, "A game theoretical study of cooperative advertising in a single-manufacturer-two-retailers supply chain," International Journal of Advanced Manufacturing Technology, vol. 74, no. 1-4, pp. 101-111, 2014.

[9] E. Castillo, J. M. Sarabia, J. M. Sarabia, and A. M. Gonzalez, "Some models for demand functions with advertising," Central European Journal of Operations Research (CEJOR), vol. 7, no. 2, pp. 71-92, 1999.

[10] T. V. Krishnan and D. C. Jain, "Optimal dynamic advertising policy for new products," Management Science, vol. 52, no. 12, pp. 1957-1969, 2006.

[11] S. Karray and G. Zaccour, "Effectiveness of coop advertising programs in competitive distribution channels," International Game Theory Review, vol. 9, no. 2, pp. 151-167, 2007. 
[12] J. G. Szmerekovsky and J. Zhang, "Pricing and two-tier advertising with one manufacturer and one retailer," European Journal of Operational Research, vol. 192, no. 3, pp. 904-917, 2009.

[13] S. Karray and G. Martín-Herrán, "A dynamic model for advertising and pricing competition between national and store brands," European Journal of Operational Research, vol. 193, no. 2, pp. 451-467, 2009.

[14] R.-L. Yan, "Managing channel coordination in a multi-channel manufacturer-retailer supply chain," Industrial Marketing Management, vol. 40, no. 4, pp. 636-642, 2011.

[15] M. M. SeyedEsfahani, M. Biazaran, and M. Gharakhani, "A game theoretic approach to coordinate pricing and vertical coop advertising in manufacturer-retailer supply chains," European Journal of Operational Research, vol. 211, no. 2, pp. 263-273, 2011.

[16] M. Kunter, "Coordination via cost and revenue sharing in manufacturer-retailer channels," European Journal of Operational Research, vol. 216, no. 2, pp. 477-486, 2012.

[17] B. Liu, G.-S. Cai(George), and A. A. Tsay, "Advertising in asymmetric competing supply chains," Production and Operations Management, vol. 23, no. 11, pp. 1845-1858, 2014.

[18] M. K. Sayadi and A. Makui, "Feedback Nash equilibrium for dynamic brand and channel advertising in dual channel supply chain," Journal of Optimization Theory and Applications, vol.161, no. 3, pp. 1012-1021, 2014.

[19] X.-P. Hong, L. Xu, P. Du, and W. Wang, "Joint advertising, pricing and collection decisions in a closed-loop supply chain," International Journal of Production Economics, vol. 167, pp. 1222, 2015.

[20] X.-L. He, A. Prasad, and S. P. Sethi, "Cooperative advertising and pricing in a dynamic stochastic supply chain: feedback stackelberg strategies," Production and Operations Management, vol. 18, no. 1, pp. 78-94, 2009.

[21] S. Karray and S. H. Amin, "Cooperative advertising in a supply chain with retail competition," International Journal of Production Research, vol. 53, no. 1, pp. 88-105, 2015.

[22] M. S. Hutchins, Cooperative Advertising, Roland Press, New York, NY, USA, 1953.

[23] M. Bergen and G. John, "Understanding cooperative advertising participation rates in conventional channels," Journal of Marketing Research, vol. 34, no. 3, pp. 357-369, 1997.

[24] S. Van Baal and C. Dach, "Free riding and customer retention across retailers' channels," Journal of Interactive Marketing, vol. 19, no. 2, pp. 75-85, 2005.

[25] W. S. Yoo and E. Lee, "Internet channel entry: a strategic analysis of mixed channel structures," Marketing Science, vol. 30, no. 1, pp. 29-41, 2011.

[26] X. Yue and J. Liu, "Demand forecast sharing in a dual-channel supply chain," European Journal of Operational Research, vol. 174, no. 1, pp. 646-667, 2006.

[27] C. A. Ingene and M. F. Parry, Mathematical Models of Distribution Channels, Springer, New York, NY, USA, 2004.

[28] D. Q. Yao and J. J. Liu, "Competitive pricing of mixed retail and e-tail distribution channels," Omega, vol. 33, no. 3, pp. 235-247, 2005. 


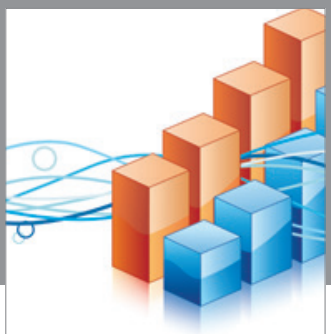

Advances in

Operations Research

vatem alat4

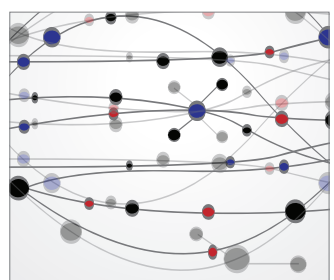

\section{The Scientific} World Journal
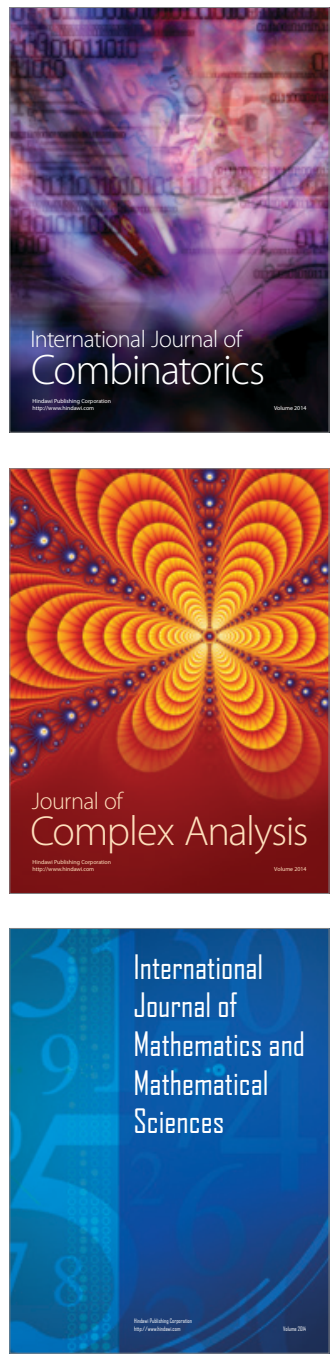
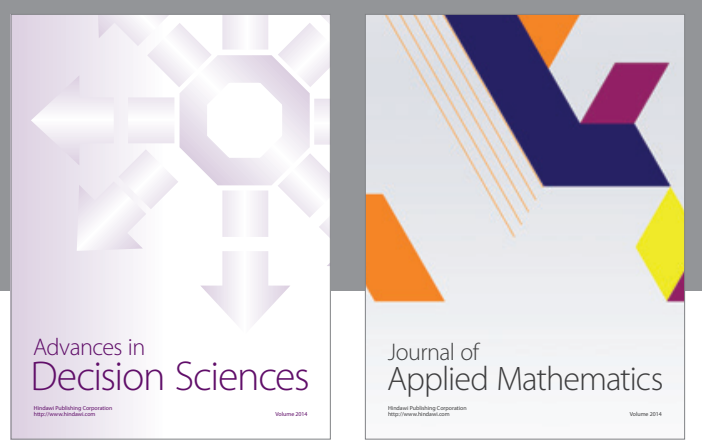

Algebra

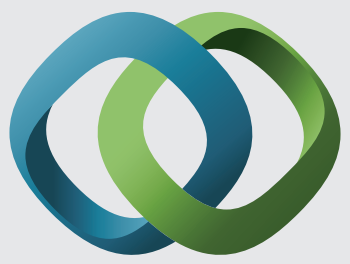

\section{Hindawi}

Submit your manuscripts at

http://www.hindawi.com
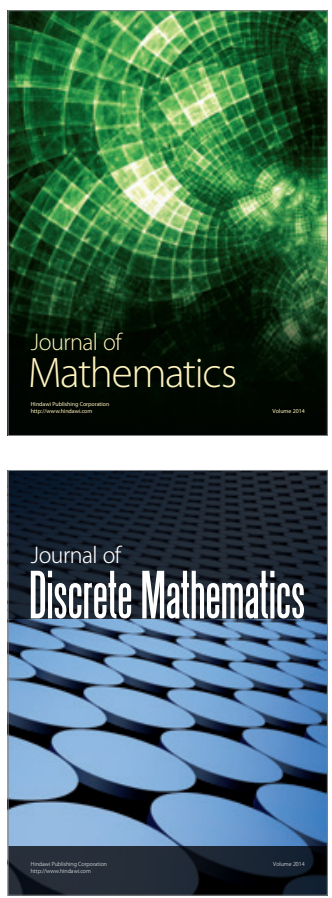

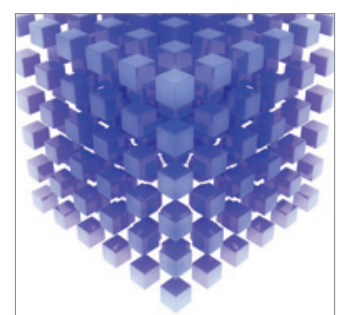

Mathematical Problems in Engineering
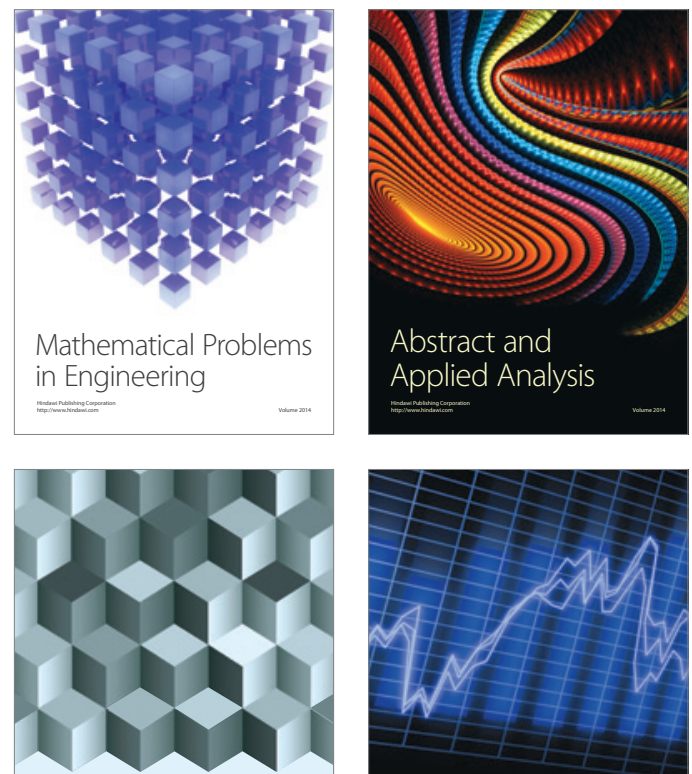

Journal of

Function Spaces

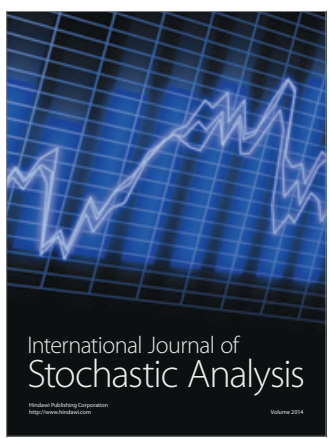

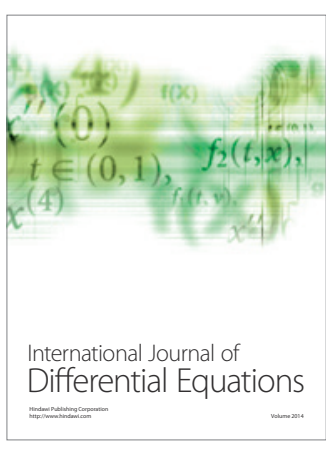
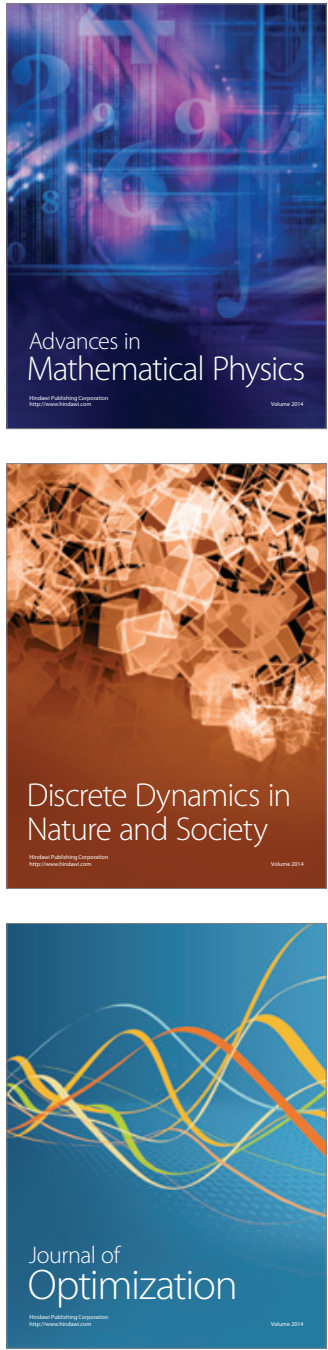